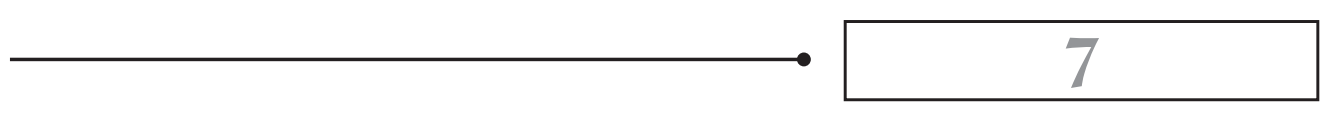

\title{
DAS REGRAS SOBRE A APLICAÇÃO DAS RECEITAS PETROLÍFERAS
}

\subsection{NOTAS INTRODUTÓRIAS}

Após todo o trabalho desenvolvido no sentido de caracterizar as receitas auferidas pelo Estado brasileiro com a venda do petróleo como uma receita de capital, chegou o momento de analisar as consequências dessa alteração de paradigma interpretativo na sua aplicação.

Conforme exposto, o artigo 44 da Lei de Responsabilidade Fiscal veda a utilização de receitas de capital no financiamento de despesas correntes (basicamente, pagamento de pessoal e material de consumo). Assim, uma vez aceita a tese proposta neste estudo, as receitas petrolíferas somente poderiam ser utilizadas na realização de investimentos e inversões financeiras (despesas de capital), o que impediria, tal qual vem sendo feito, a sua aplicação em despesas correntes, que, conforme defendido pela doutrina econômica, não propicia a reprodução do capital e, consequentemente, um desenvolvimento de longo prazo capaz de beneficiar as geraçóes futuras quando do esgotamento das jazidas.

Tal orientação econômica para que as rendas do petróleo sejam aplicadas em investimentos baseia-se, ao fim e ao cabo, nas mesmas razões pelas quais não se deve aplicar uma receita oriunda da alienação de um bem em despesas correntes, tal qual exposto na seção $5.4 .2 \mathrm{com}$ o exemplo da família, oportunidade em que foi explicada a lógica do artigo 44 da Lei de Responsabilidade Fiscal. Ambos são recursos que não podem sustentar o padrão de vida de uma população no longo prazo, uma vez que a receita auferida com a venda de um bem hoje não mais estará disponível amanhã, a não ser que seja investida de modo a propiciar o aumento da riqueza do país. 
Vale destacar, contudo, que embora não exista, até o momento, um estudo que atribuísse às receitas petrolíferas natureza de receitas de capital (o que por si só impõe um maior cuidado com o seu gasto), verificam-se no ordenamento jurídico dos países beneficiados com recursos naturais, sobretudo quando não renováveis, regras específicas que impõem um controle mais rigoroso à sua utilização, com a finalidade de evitar que venham a sofrer com a chamada "Maldição do Petróleo".

Referida "maldição" consiste em uma situação paradoxal que se verifica em grande parte dos países produtores de petróleo. Estes, apesar de beneficiados com uma expressiva arrecadação de receitas públicas, decorrente da venda do petróleo, não conseguem promover o seu desenvolvimento, figurando, muitos deles, entre os países com o menor Índice de Desenvolvimento Humano do mundo.

No intuito de compreender esse efeito nocivo das rendas petrolíferas, diversos estudos foram formulados visando detectar suas causas e propor soluções para o problema. Muitos deles findaram por inspirar a formulação de normas jurídicas, por meio das quais se conferiu um maior controle à utilização dessas receitas pelos países produtores de petróleo.

Nesse contexto, para que se possa chegar ao objetivo final deste estudo, que é analisar as limitações ao gasto das receitas petrolíferas decorrente da mudança de interpretação acerca da sua natureza jurídica, expõe-se, inicialmente, em que consiste a maldição do petróleo, verificando suas causas e possíveis soluções, o que é de fundamental importância para que se compreenda, na seção seguinte, o porquê de certas restriçôes legislativas ao gasto dessas receitas no ordenamento jurídico brasileiro.

Visto isso, chega-se ao final deste capítulo, em que se busca responder aos seguintes questionamentos:

1) Como deve ser operacionalizada essa mudança?

2) De que maneira essa alteração irá se compatibilizar com as regras atuais de limitação desses recursos?

3) Quais as vantagens e eventuais dificuldades em se limitar o gasto das receitas petrolíferas com despesas de capital?

\subsection{A MALDIÇÃO DO PETRÓlEO}

Muitos países, apesar de ricos em recursos naturais, não foram capazes de utilizar essa benesse da natureza para promover o seu desenvolvimento, apresentando, de maneira geral, desempenho pior do que outros com menores quantidades de recursos naturais - o oposto daquilo que se esperaria. Esse fenômeno ficou conhecido como "a maldição dos recursos naturais" e foi objeto de uma série de estudos que tentaram encontrar as causas e soluçóes para esse problema. 
Ao tratar especificamente dos efeitos dessa maldição sobre os países produtores de petróleo, Terry Lynn Karl ensina que após quatro décadas de experiência, constatou-se que a exportação de petróleo em si não transforma países pobres em economias prósperas. Antigamente, afirma a autora, "muitos especialistas pensavam que o ouro negro traria riquezas e desenvolvimento econômico. Atualmente as expectativas são muito mais contidas" (2005, p. 22). Nesta perspectiva, "seria mais apropriado descrever os países exportadores de petróleo como países que sofrem do paradoxo da abundância, do problema do Rei Midas, ou o que Juan Pablo Perez Alfonzo, fundador da OPEP, chamou de os efeitos do excremento do diabo" (KARL, 2005, p. 22).

De fato, verifica-se que, de maneira geral, os países que dependem do petróleo para sua sobrevivência estão entre aqueles economicamente mais fragilizados, marcados por governos autoritários e dominados por conflitos.

Os efeitos prejudiciais incluem um crescimento econômico menor do que o esperado, uma fraca diversificação econômica, indicadores sociais baixos, altos níveis de pobreza e desigualdade, impactos ambientais devastadores ao nível local, corrupção desenfreada, governança excepcionalmente insatisfatória e grandes incidências de conflito e guerra (KARL, 2005).

Quando comparados a países que dependem da exportação de commodities agrícolas, Karl aduz que os países exportadores de petróleo e minérios sofrem com situações incomuns de grande pobreza, "sistema de saúde deficiente, má nutrição generalizada, altas taxas de mortalidade infantil, baixa expectativa de vida e baixo desempenho escolar - descobertas surpreendentes, considerando os fluxos de receitas em países ricos em recursos naturais" (2005, p. 22).

Contudo, percebe-se que essa maldição não é uma "sina" que necessariamente atinge todos os países que se encontram na posição de grandes produtores de recursos naturais. Conforme exemplifica Stiglitz, há aproximadamente 30 anos a Indonésia e a Nigéria apresentavam rendimentos per capita semelhantes e ambas dependiam intensamente das receitas petrolíferas. "Atualmente, o rendimento per capita da Indonésia é quatro vezes maior do que o da Nigéria, que caiu de US\$ 302,75 em 1973 para US\$254,16 em 2002" (2005, p. 13).

Da mesma forma, Karl entende que a maldição dos recursos naturais não é uma afirmação de que a sua abundância é sempre ou inevitavelmente ruim para o crescimento econômico ou para o desenvolvimento. A autora aponta exemplos de desenvolvimento bem-sucedido com base em recursos naturais, incluindo os "Estados Unidos (que foram a principal economia mineral do mundo quando se tornaram o líder mundial em manufaturas), o Canadá, a Austrália, o Chile e a Noruega" (2005, p. 22). 
Neste sentido, começou-se a entender que o problema da maldição dos recursos naturais não estaria associado à mera propriedade de petróleo ou outros minerais, mas sim ao uso ineficiente das receitas públicas arrecadadas em razão da sua alienação.

A partir de então, surgiu uma série de estudos voltados a evitar essa maldição, ou mesmo revertê-la, identificando as suas causas e propondo soluçôes, as quais findaram por influenciar a adoção de políticas públicas de responsabilidade na gestão fiscal dessas receitas por diversos países, dentre eles o Brasil. É o que se verá adiante.

\subsubsection{Causas da maldição do petróleo}

De acordo com as lições de Terry Lynn Karl (2005), Stiglitz (2005) e Serra (2006), as causas para o fraco desempenho econômico dos países produtores de petróleo podem ser sumarizadas em seis fatores: 1) volatilidade do preço do petróleo, 2) doença holandesa, 3) defasagem na capacitação local, 4) ausência de diversificação de fontes de arrecadação tributária, 5) corrupção, e 6) utilização em despesas correntes. Aborda-se de maneira resumida cada um deles.

1) Volatilidade do preço do petróleo: o preço do petróleo caracteriza-se por fortes oscilações no mercado, sendo conhecido como um dos mais voláteis do mundo. Isso dificulta sobremaneira o planejamento dos gastos públicos, principalmente quando há uma participação exacerbada deste recurso na composição do PIB do país. ${ }^{60}$ Se a dependência for muito grande, a queda do petróleo, por exemplo, de 100 para 50 dólares o barril em um mês, cortaria praticamente pela metade a sua arrecadação de maneira brusca, o que o levaria a se endividar para cobrir suas despesas. Ao lançar mão do endividamento, a sua situação tende a se agravar, conforme explica Stiglitz:

Quando o preço do petróleo está em alta, os bancos se dispõem a emprestar dinheiro para aumentar a taxa de dispêndio. Entretanto, os mercados de capitais são amigos inconstantes e volúveis. Quando o preço do petróleo cai ou as taxas de juros aumentam, os credores são rápidos para cobrar os empréstimos. A máxima característica dos banqueiros é que eles preferem emprestar para aqueles que não precisam do dinheiro. Quando o preço do petróleo cai, o país precisa de dinheiro, mas é nessa situação que os credores querem reaver seu dinheiro. Isto explica porque os fluxos de capital, especialmente os de curto prazo, tendem a ser pró-cíclicos, exagerando, de qualquer forma, as flutuações geradas pela queda do preço do recurso natural (2005, p. 15).

60 "Esta dependência geralmente é medida pela participação majoritária das exportações de petróleo nas exportações totais (geralmente de 60 a 95\% das exportações totais) ou pelo quociente entre exportaçôes de petróleo e gás natural, e o produto interno bruto - um número que pode variar de 4,9\% (em Camaróes, cujo petróleo está se exaurindo) a 86\% (na Guiné Equatorial, um dos mais novos exportadores)" (KARL, 2005, p. 22). 
2) Doença holandesa: a doença holandesa corresponde a um processo de desindustrialização que pode ocorrer em um país ao descobrir reservas de petróleo em seu território. A exportação do recurso, e a consequente entrada de capital estrangeiro, leva à valorização da moeda do país, tornando mais atrativas as importações em detrimento das exportações, prejudicando, assim, a competitividade da indústria nacional.

3) Defasagem na capacitação local: segundo Terry Lynn Karl, a dificuldade das companhias petrolíferas em aproveitar a mão de obra local, em virtude da baixa capacitação profissional da população economicamente ativa dos países exportadores de petróleo, resulta no enfraquecimento da demanda por conhecimento no país. De acordo com a autora:

profissionais altamente especializados são enviados a outros países para serem treinados, ou então profissionais estrangeiros são trazidos para o país para trabalhar, tirando assim dos países exportadores de petróleo os imensos benefícios do processo de aprendizagem pela experiência, crucial para o desenvolvimento econômico (2005, p. 24).

Afirma ainda que esse impacto é evidente de acordo com o Segundo Relatório de Desenvolvimento Humano em Países Árabes, publicado pela Organização das Nações Unidas em 2003, segundo o qual "a alta dependência do petróleo em partes do Oriente Médio levou à superconcentração de riquezas em poucas mãos, ao deficiente crescimento econômico, e enfraqueceu a demanda por conhecimento" (2005, p. 24).

4) Ausência de diversificação de fontes de arrecadação tributária: é muito comum em países que são grandes produtores de petróleo que sua arrecadação esteja pautada, unicamente, na apropriação de rendas decorrentes da venda deste recurso. Tem-se verificado que a abundância de petróleo em uma região retira os incentivos à instituição de um sistema tributário que gere outras fontes de renda para o Estado, o que aprofunda a dependência com relação a esta fonte de renda.

Além disso, a ausência de imposição tributária à população local gera, segundo Karl, o rompimento de uma ligação crítica entre tributação, representação e responsabilidade do Estado. "A dependência do petróleo funciona como uma barreira para atividades mais produtivas, e elimina a responsabilidade necessária para satisfazer as demandas e o escrutínio dos contribuintes" (2005, p. 24).

5) Corrupção: grandes produtores de petróleo, a exemplo de Nigéria, Angola, Azerbaijão, Congo, Camarôes e Indonésia, entre outros, "competem pela posição de o país mais corrupto na classificação anual da Transparência Internacional, uma organização não governamental dedicada a 
combater governos e práticas comerciais internacionais corruptas" (KARL, 2005, p. 26). Muitas vezes os governantes firmam contratos com as companhias de petróleo, beneficiando-se diretamente das receitas petrolíferas auferidas. Há situações em que estes valores chegam a ser depositados em contas pessoais desses representantes (vide exemplo da Líbia, bastante difundido na mídia, em que os royalties eram depositados nas contas pessoais do ex-ditador Muhammad Gaddafi e de seus filhos). Grupos políticos desviam as receitas do petróleo em seu favor para se manter no poder, reprimindo violentamente manifestações contrárias a seus regimes. Essa situação causa ainda mais distorções econômicas, segundo Karl, pois "diminui a eficiência dos investimentos, fortalece a oposição à reforma econômica e permite a formação de distorções nas barreiras protecionistas" (2005, p. 26).

Além disso, prossegue a autora, "elevados níveis de corrupção contribuem para a maldição dos recursos naturais, pois alteram as escolhas das políticas públicas". Neste sentido, por exemplo, os planejadores em países exportadores de petróleo "tendem a favorecer megaprojetos cujas compensações podem ser mais facilmente ocultadas e a obtenção de subornos facilitada, enquanto evitam investimentos produtivos de longo prazo mais transparentes" (KARL, 2005, p. 26). Esta situação leva à diminuição tanto dos níveis de crescimento como de renda do país.

6) Utilização em despesas correntes: a mera utilização das receitas petrolíferas em despesas correntes, por si só, é vista por parte da doutrina econômica como prejudicial para a qualidade do gasto público, propiciando a deterioração das finanças dos países produtores de petróleo. Isso porque não faz sentido utilizar esses recursos para o custeio da máquina estatal se, após o período de extração, findas as reservas, não será mais possível sustentar o padrão anteriormente criado. Nesse diapasão, Rodrigo Valente Serra argumenta que "se espera que esta renda gerada seja aplicada de forma a oferecer à geração futura uma fonte de renda, quando da exaustão do recurso" (2006, p. 210). Segundo o autor, baseando-se nas liçōes de Hartwick (1977), recomenda-se que as rendas geradas por recursos não renováveis sejam investidas em acumulação de bens de capital. "A ideia é que a geração atual deixe para a futura capital reprodutível, humano ou físico, suficiente para que esta mantenha um padrão de vida satisfatório" (SERRA, 2006, p. 210). Para tanto, continua, "a geração atual deve converter parte da renda de Hotelling em máquinas e trabalho. É a transformação de estoque de recursos não renováveis em estoques de capital manufaturado e humano" (SERRA, 2006, p. 210-211). 
Este último fator apontado como causa para a maldição do petróleo (aplicação das rendas petrolíferas em despesas correntes) se conecta da maneira mais direta ao escopo desta tese, motivo por que será visto com mais detalhes adiante. Verificar-se-á, inclusive, que boa parte das soluções prescritas para a eliminação desse mal se baseia na utilização desses recursos em despesas de capital, capazes de gerar o financiamento e a diversificação da economia "na direção de atividades mais dependentes de trabalho e capital físico do que de recursos naturais" (2006, p. 210211). É o que defende Serra, citando os ensinamentos de Postali.

\subsubsection{Medidas criadas para conter a maldição}

Do mesmo modo como foi feito anteriormente, nesta seção serão abordadas, de maneira sumária, algumas medidas com o intuito de combater a maldição do petróleo. Para tanto, tomam-se por base as lições de Stiglitz, que tratou do tema em artigo intitulado "Transformando os Recursos Naturais em uma Bênção em vez de uma Maldiçãa”.

As soluções propostas foram divididas no estudo em políticas macroeconômicas e microeconômicas. Dentre as primeiras, tem-se: 1) controle do nível de extração; 2) realização de empréstimos apenas para o financiamento de despesas de capital; 3) adoção de estruturas contábeis que evidenciem a conversão do petróleo (considerado um ativo) em recursos financeiros; e 4) a criação de fundos de estabilização. Com relação às políticas microeconômicas, foram sugeridas a) a adoção de mecanismos de transparência e b) de modelos de licitação eficientes.

\section{Políticas macroeconômicas:}

1) Controle do nível de extração: o Estado deve desenvolver mecanismos que possibilitem o controle da taxa de extração do recurso, tendo em vista que, em determinadas circunstâncias, poderá ser economicamente mais eficiente deixá-lo por algum tempo sob a terra, aguardando situações mais favoráveis para extraí-lo.

Além disso, a extração de recursos naturais não renováveis diminui a riqueza de um país, a menos que as receitas geradas sejam investidas de modo a propiciar o seu aumento. Segundo Stiglitz, a extração em si faz com que o país empobreça, uma vez que recursos como petróleo, gás natural ou minérios não são renováveis. "Uma vez retirados do solo e vendidos, não podem ser repostos. Somente o reinvestimento subsequente 
em bens de capital (físicos ou naturais) pode compensar a perda desta riqueza natural e fazer com que o país fique mais rico (2005, p. 15).

Como os recursos naturais são bens que integram o ativo do Estado, continua o autor, deve-se considerar a extração simplesmente como uma redistribuição de portfólio, ao converter uma parte da base de ativos dos recursos naturais em uma outra forma. "Um país como Bangladesh, com reservas limitadas de gás natural, pode querer agir com cautela ao vender seu gás, já que não há nenhuma outra maneira efetiva de assegurar-se com relação a um aumento no preço da energia no decorrer do tempo" (2005, p. 15).

2) Realização de empréstimos apenas para o financiamento de despesas de capital: essa é a chamada Regra de Ouro das Finanças Públicas, segundo a qual as operações de crédito efetuadas por um país não devem exceder o montante previsto em seu orçamento para a realização de despesas de capital. Dito de outro modo, não se deve realizar empréstimos para o financiamento de despesas correntes.

Essa é uma preocupação especialmente relevante nos países produtores de petróleo, pois, conforme demonstra a experiência, há uma tendência de estes realizarem vultosos empréstimos quando há uma queda brusca no preço do petróleo (o que não é incomum ocorrer, dada a volatilidade do preço deste recurso). Como alguns utilizam as rendas petrolíferas para cobrir despesas correntes, que de modo geral precisam ser efetivadas com certa regularidade (por exemplo, o pagamento de pessoal), uma diminuição expressiva no preço do barril leva aqueles cujo orçamento depende em grande parte desses valores a contratarem empréstimos para conseguir manter o nível dos serviços públicos existentes.

Ademais, como bem exposto por Stiglitz, quando o dinheiro do empréstimo é usado para financiar despesas correntes, "essas despesas podem contribuir para a supervalorização da taxa de câmbio, o que em realidade gera grandes dificuldades para exportadores e fornecedores através de um efeito conhecido como a Doença Holandesa" (2005, p. 15).

3) Adoção de estruturas contábeis que evidenciem a conversão do petróleo (considerado um ativo) em recursos financeiros: neste ponto, Stiglitz faz uma crítica à ausência de contabilização do petróleo como ativo permanente do patrimônio estatal e afirma que:

Da mesma forma que as estruturas contábeis de uma firma levam em conta a depreciação de seus ativos, uma estrutura contábil de um país deve levar em conta o esgotamento de seus recursos naturais e a deterioração do meio ambiente. Da mesma 
forma que a estrutura contábil de uma firma considera ativos e passivos, um país também deveria considerar os seus, observando se há aumento do passivo (dívidas) assim como do ativo. Um país que liquida seus recursos naturais, privatiza suas companhias petrolíferas e contrai empréstimos a serem pagos com receitas futuras, pode passar por uma febre de consumo que eleva o PIB, mas a estrutura contábil deveria demonstrar que, em verdade, o país ficou mais pobre (2005, p. 16).

Essa é uma crítica que corrobora o posicionamento defendido ao longo do trabalho de que os pagamentos efetuados pelas empresas petrolíferas por meio dos royalties lato sensu correspondem, na verdade, à contraprestação pela alienação de um bem público, cuja propriedade é transferida ao particular no momento da extração. A ausência de contabilização desses recursos naturais no ativo permanente do Estado gera a falsa impressão de que, com o recebimento dessas receitas, houve apenas um acréscimo no patrimônio público, desconsiderando, portanto, que se deu também um decréscimo no seu ativo permanente.

4) Criação de fundos de estabilização: tal medida mostra-se de suma importância para proteger os Estados contra as oscilações do preço do petróleo, pois o dinheiro ali depositado permite a realização de uma política anticíclica, poupando-se no período em que os preços estão em alta, para que haja receitas disponíveis quando da desvalorização do recurso. $\mathrm{Na}$ maioria dos casos - como ocorre no Brasil - esses fundos acumulam também a função de fundos de investimento, de modo que o esgotamento dos recursos naturais seja compensado por um aumento no capital humano e físico.

\section{Políticas microeconômicas:}

a) Adoção de mecanismos de transparência: a divulgação por parte do Estado de informaçóes como os termos dos contratos petrolíferos firmados, o montante de receita paga ao governo, a quantia de recursos naturais extraídos, eventuais benefícios fiscais existentes, a forma de utilização das receitas arrecadadas, entre outros aspectos, é uma das formas mais eficientes de combater a corrupção, pois possibilita o controle das ações estatais não só pela população local, mas também pelas próprias empresas petrolíferas e organismos internacionais.

b) Modelos de licitação eficientes: o modelo de licitação adotado traz consequências importantes na forma como o governo irá se apropriar da riqueza gerada com a extração dos seus recursos. Stiglitz refere duas situações que podem gerar distorçôes indesejáveis para o país. A primeira delas diz respeito à extensão dos campos licitados. Um certame no qual há 
uma divisão do espaço a ser explorado em poucos blocos de grande extensão, em vez de muitos blocos de tamanho reduzido, diminui a competitividade e, consequentemente, os incentivos para que as empresas ofereçam uma participação governamental mais alta na extração dos recursos durante o processo licitatório. Tal problema, contudo, somente se verifica quando a porcentagem da participação estatal (estabelecida por meio de royalties lato sensu ou de uma parcela do óleo extraído) serve de parâmetro para a escolha do licitante vencedor. Isso certamente ocorrerá no Brasil com os contratos de partilha, em que vence a empresa que oferecer uma maior parcela do excedente em óleo à União.

A segunda distorção diz respeito a uma eventual vantagem de se adotar uma alíquota regressiva para os royalties lato sensu como uma forma de evitar o fechamento prematuro dos campos de extração, ou mesmo que haja uma retirada excessivamente alta de óleo. Contratos bem elaborados, afirma Stiglitz, "podem ter um termo que permita, à medida que o petróleo comece a ser extraído e os custos de extração aumentem, a diminuição (ou possivelmente até a eliminação) dos royalties mediante o pagamento de um montante fixo" (2005, p. 18).

\subsection{REGRAS DE LIMITAÇÃO AO USO DAS RECEITAS PETROLÍFERAS NO BRASIL}

Muitas dessas medidas sugeridas pelos economistas foram adotadas por países produtores de petróleo e inspiraram a formulação de normas jurídicas por meio das quais se conferiu um controle maior à utilização das receitas públicas auferidas em razão da venda desses recursos.

No Brasil, as primeiras limitações ao uso das receitas petrolíferas foram introduzidas na Lei n. 2.004/53, que previa regras distintas caso se tratasse de recursos auferidos pela União ou por Estados, Municípios e Distrito Federal. Com relação ao ente central, desde esse momento as restrições legais caracterizavam-se por ser bastante amplas, apenas impondo a vinculação de uma parcela dos recursos a atividades desenvolvidas pelos Ministérios de Minas e Energia, Educação e Cultura, e Marinha, que poderiam servir, inclusive, para cobrir despesas correntes desses órgãos.

No que tange à parcela direcionada aos entes subnacionais, de acordo com essa norma deveria ser aplicada "preferentemente em energia, pavimentação de rodovias, abastecimento e tratamento de água, irrigação, proteção ao meio ambiente e saneamento básico”. Em 22 de julho de 1986, a Lei n. 7.525 alterou o dispositivo, substituindo a palavra "preferentemente" por "exclusivamente". 
Com a edição da Lei n. 7.990, de 28 de dezembro de 1989, que revogou a Lei n. 2.004/53, introduziram-se no ordenamento novas limitações ao gasto das rendas petrolíferas (RCCs apenas). As mais significativas referiam-se apenas aos entes subnacionais, vedando-se a aplicação das compensações financeiras por eles percebidas no pagamento de dívidas e de pessoal. ${ }^{61}$ Além disso, tais esferas de poder continuaram obrigadas - ao menos em tese - a aplicar esses recursos como previsto na legislação anterior, exclusivamente em "energia, pavimentação de rodovias, abastecimento e tratamento de água, irrigação, proteção ao meio ambiente e em saneamento básico", por força do comando contido no art. 24 do Decreto n. 1, de 11 de janeiro de 1991. A União, por sua vez, permaneceu obrigada apenas a direcionar parcela dos seus recursos a órgãos da sua administração direta; em um primeiro momento (por força da Lei n. 7.990/89), somente para o Ministério da Marinha, para fazer frente aos encargos de fiscalização na plataforma continental. Depois, com a edição da Lei n. 9.478/97, novamente para o Ministério de Minas e Energia, bem como para os Ministérios de Meio Ambiente e Ciência e Tecnologia, como visto no capítulo anterior, para fazer frente a uma série de programas e projetos vinculados a esses órgãos.

Contudo, verifica-se na prática que todas essas vinculações passam ao largo de ser cumpridas. A União, conforme ensinam Afonso e Gobetti, transfere apenas uma pequena parcela do que a legislação determina, contingenciando a maior parte dos recursos para a realização de superávit primário:

$\mathrm{Na}$ esfera federal de governo, por sua vez, os recursos são expressamente vinculados a determinados programas e Ministérios (Marinha, Minas e Energia, Meio Ambiente e Ciência e Tecnologia), mas a regra tampouco tem sido obedecida. Por meio de desvinculaçôes formais e contingenciamentos do orçamento dos ministérios, o Tesouro Nacional tem desviado para o superávit primário a maior parte da receita dos royalties que permanece com a União, como podemos ver na Tabela 6, onde sistematizamos informações do banco de dados Siga Brasil, do Senado.

Entre 2003 e 2007, o total arrecadado pelo Tesouro em royalties e participaçôes especiais chegou a $\mathrm{R} \$ 64$ bilhōes, dos quais $\mathrm{R} \$ 39$ bilhōes foram transferidos para estados e municípios. Os $\mathrm{R} \$ 25$ bilhôes restantes estavam vinculados aos orçamentos dos

61 Art. 8' O pagamento das compensações financeiras previstas nesta Lei, inclusive o da indenização pela exploração do petróleo, do xisto betuminoso e do gás natural será efetuado, mensalmente, diretamente aos Estados, ao Distrito Federal, aos Municípios e aos órgãos da Administração Direta da União, até o último dia útil do segundo mês subsequente ao do fato gerador, devidamente corrigido pela variação do Bônus do Tesouro Nacional (BTN), ou outro parâmetro de correção monetária que venha a substituí-lo, vedada a aplicação dos recursos em pagamento de dívida e no quadro permanente de pessoal. (Lei n. 7.990/89, grifos nossos). 
Ministérios da Defesa (Marinha), Ciência e Tecnologia, Minas e Energia e Meio Ambiente. Mas apenas R \$ 3,4 bilhões desse total foram efetivamente aplicados pelo Tesouro em sua finalidade legal (2008, p. 249).

Com relação aos entes subnacionais, a situação não é diferente. A desconhecida vinculação de recursos prescrita no citado art. 24 do Decreto n. 1/91 é simplesmente tratada como se não existisse. A proibição de aplicação das compensações financeiras em gasto com pessoal perdeu grande parte de sua eficácia com a interpretação que vem sendo dada atualmente a essa regra pelos Tribunais de Contas do país.

Ocorre que de acordo com o entendimento das Cortes Estaduais de Contas do país (exceto os TCs do Espírito Santo e Paraná), a vedação contida no art. $8^{\circ}$ da Lei n. 7.990/89 - que proíbe a aplicação das compensações financeiras em despesas com pessoal - não impede que essas receitas integrem o cálculo da Receita Corrente Líquida do ente federativo (RCL). O problema é que, tendo em vista que a LRF cria um limite para gasto com pessoal baseado numa fração da RCL (União 60\%, Estados e Municípios 50\%), ${ }^{62}$ a inclusão das compensações financeiras no cômputo da Receita Corrente Líquida finda por propiciar que boa parte desses recursos seja aplicada em despesas com pessoal.

Eis como se posicionaram sobre o tema os técnicos designados pelos Tribunais de Contas e órgãos representativos do Governo Federal, que se reuniram no IV FÓRUM IRB/PROMOEX, com o objetivo de harmonizar os conceitos e pontos de controle da LRF:

O Tribunal de Contas do Estado do Paraná, através do Acórdão n. 1.509/06, de 10/11/2006, decidiu pela exclusão das receitas de Transferências Voluntárias, de recursos de transferência do Sistema Único de Saúde, dos Royalties de Compensaçôes Financeiras e do Salário Educação/FNDE do cálculo da Receita Corrente Líquida, tendo em vista tratar-se de verbas vinculadas a finalidades específicas e de natureza transitória. O representante do TCE-PR, Márcio Assumpção, informou que foi utilizado como fundamento para tal exclusão a Lei n. $\mathbf{7 . 9 9 0 / 8 9}$, bem como o parágrafo único do art. $8^{\circ}$ da LRF.

Os defensores da tese da exclusão dos recursos vinculados e transitórios alegam que, se considerados esses recursos, os limites ficarão bem superiores à capacidade real de endividamento ou absorção de despesas correntes do ente público. Foram citados

62 Art. 19. Para os fins do disposto no caput do art. 169 da Constituição, a despesa total com pessoal, em cada período de apuração e em cada ente da Federação, não poderá exceder os percentuais da receita corrente líquida, a seguir discriminados: I - União: 50\% (cinquenta por cento); II - Estados: 60\% (sessenta por cento); e III - Municípios: 60\% (sessenta por cento). 
exemplos de Municípios que comprometem mais de $\mathbf{1 0 0} \%$ (cem por cento) das suas receitas correntes, excluídos os recursos oriundos dos royalties do petróleo, com despesa de pessoal.

A representante da STN, Selene Peres, defendeu que a concepção da RCL não segue a lógica orçamentária, à qual se atrelam as vinculações. Sua finalidade é servir de parâmetro ou denominador para definição e apuração dos limites máximos previstos pela LRF. Os limites, por sua vez, são tetos para gasto e não autorizam despesas; apenas o orçamento autoriza despesas. Não tendo a LRF citado tais receitas vinculadas no rol das exclusóes possíveis, deveriam as mesmas compor a receita corrente líquida dos respectivos entes. [...]

O entendimento majoritário foi o de que não há fundamentação jurídica plausível para a exclusão das receitas vinculadas (royalties, SUS, Salário Educação do FNDE e Transferências Voluntárias) da base de cálculo para a Receita Corrente Líquida (2007, p. 7-8, grifos nossos).

O resultado de tal entendimento, conforme denunciam Afonso e Gobetti, é a utilização indiscriminada dessas receitas para o pagamento de pessoal:

Além disso, como veremos a seguir, os municípios sobrefinanciados, mais ricos, tendem a gastar mais não só em áreas essenciais como, principalmente, em outras menos prioritárias. As despesas com pessoal do Legislativo, por exemplo, estão limitadas a 6\% da receita corrente líquida na esfera municipal (LC n. 101/2000). Isso significa que o aumento das transferências provenientes de royalties cria um estímulo, via aumento da RCL, para que as Câmaras de Vereadores utilizem o espaço fiscal que possuem para elevar suas despesas.

[...] Em geral, e não apenas nos Legislativos, os gastos com pessoal são mais elevados no grupo dos cem principais beneficiários dos royalties, ultrapassando em $33 \%$ a média per capita dos demais municípios recebedores desse tipo de compensação financeira, apesar de a Lei n. 7.990/89 ter proibido a aplicação desse tipo de receita em pagamento de dívidas e no quadro permanente de pessoal. No período de 2002 a 2006, as despesas de pessoal nos vinte principais beneficiários de royalties cresceram $70,7 \%$ em valores nominais, o dobro da inflação do período. Em Campos (RJ), a expansão chega a 306,9\%.

Ou seja, podemos falar em uma propensão de os municípios gastarem a riqueza do petróleo em ampliação das despesas correntes, em especial as despesas de pessoal. Por outro lado, é possível verificar que essa expansão das despesas correntes sequer está relacionada à expansão dos serviços públicos disponibilizados à população. A Tabela 5 mostra que não há diferença de investimentos (em obras e equipamentos) per capita entre os grupos de municípios, segundo o recebimento ou não de royalties (2008, p. 246-247).

Verifica-se, portanto, que grande parte dos recursos auferidos pelos entes subnacionais a título de compensação financeira é utilizada no pagamento de pessoal 
(espécie de despesa corrente), o que, conforme apontado na seção anterior, constitui uma das mais significativas causas para a maldição do petróleo (ou enfraquecimento da economia em razão do recebimento de receitas petrolíferas), tendo em vista que a aplicação desses recursos nesse tipo de finalidade não propicia a reprodução do capital e, consequentemente, um desenvolvimento de longo prazo. Essa situação por que passam os entes subnacionais brasileiros beneficiários de receitas petrolíferas mostra-se especialmente preocupante diante da constatação de que praticamente não há diferença no montante de investimentos (em obras e equipamentos) per capita entre os grupos de municípios receptores ou não de compensações financeiras, de acordo com as conclusões do estudo empírico formulado por Afonso e Gobetti, citadas acima.

Como será visto adiante, as diferenças de interpretação entre os Tribunais de Contas sobre a inclusão ou não das compensações financeiras no cálculo da RCL perdem a razão de existir diante do entendimento aqui proposto, de que as rendas petrolíferas constituem receitas de capital. É que, segundo o art. $2^{\circ}$, IV, da Lei de Responsabilidade Fiscal, as receitas de capital estão excluídas do cômputo da receita corrente líquida. Consequentemente, como já explicado anteriormente, uma vez classificadas como receitas de capital, somente poderão ser aplicadas por qualquer dos entes federativos em despesas de capital: investimentos e inversões financeiras (art. 44, LRF).

A partir de 2010, com a descoberta do pré-sal, novas limitações ao gasto das receitas petrolíferas passaram a ser introduzidas no ordenamento jurídico aplicáveis, todas elas tendentes, ao menos de maneira ideal, a propiciar a sua utilização em benefício das gerações futuras e na melhoria das condições de saúde e educação básica.

A Lei n. 12.858 de 9 de setembro de 2013 determinou que parcela dos royalties lato sensu fosse destinada exclusivamente para a educação pública, com prioridade para a educação básica, e para a saúde, de modo a serem aplicados em acréscimo ao mínimo obrigatório previsto na Constituição Federal.

Com relação às receitas percebidas pela União, de acordo com o artigo $2^{\circ}$ do referido diploma, deverão ser aplicadas nesta finalidade: (i) todas as receitas percebidas pelos órgãos da administração direta da União provenientes dos royalties lato sensu, auferidos por meio de qualquer modalidade contratual, quando a lavra ocorrer na plataforma continental, no mar territorial ou na zona econômica exclusiva; (ii) $50 \%$ (cinquenta por cento) dos recursos recebidos pelo Fundo Social; e (iii) as receitas da União decorrentes de acordos de individualização da produção de que trata o art. 36 da Lei n. 12.351 de 22 de dezembro de 2010. 
No que tange aos Estados, Distrito Federal e Municípios, deverão ser aplicadas na mesma finalidade as receitas provenientes dos royalties e da participação especial, sob os regimes de concessão, de cessão onerosa e de partilha de produção, quando a lavra ocorrer na plataforma continental, no mar territorial ou na zona econômica exclusiva;

Com exceção das receitas auferidas pela União, correspondentes a 50\% (cinquenta por cento) dos recursos recebidos pelo Fundo Social; e as receitas da Uniāo decorrentes de acordos de individualização da produção, vale destacar que todas as demais mencionadas acima, inclusive as destinadas aos Estados, Distrito Federal e Municípios, deverão ser aplicadas no montante de $75 \%$ (setenta e cinco por cento) na área de educação e de $25 \%$ (vinte e cinco por cento) na área de saúde.

Contudo, a alteração mais significativa na utilização das receitas petrolíferas pela União, sem dúvidas, diz respeito à criação do Fundo Social pelo art. 47 da Lei n. 12.351/2010. Dada a complexidade das normas que regulam o seu funcionamento, bem como a importância desse instrumento, reconhecido em todo o mundo como o mecanismo de maior sucesso no combate à maldição do petróleo, este será tratado mais detalhadamente no tópico a seguir.

\subsection{FUNDO SOCIAL}

Não restam dúvidas de que a medida de maior sucesso, e por isso mais difundida em todo o mundo como forma de combater os efeitos nocivos da maldição do petróleo, são os chamados fundos soberanos.

Constituem-se, segundo Sergio Gobetti, em instituições fiscais especiais cujo objetivo é tentar evitar a volatilidade das rendas do petróleo e, em alguns casos, as pressões cambiais decorrentes da internalização das receitas em divisas estrangeiras (2009, p. 15).

De acordo com Rodrigo Valente Serra:

Trata-se de um fundo com dupla finalidade: a garantia de estabilidade macroeconômica e a constituição de um fundo de poupança. A contribuição do fundo para a estabilidade macroeconômica se efetiva em duas frentes: nos momentos de alta do preço do petróleo, o fundo, ao recolher o excesso de divisas daquele grande país exportador, contribuiria para minimizar a pressão inflacionária; nas conjunturas de baixa do preço do petróleo, o fundo socorreria o Tesouro, evitando um maior nível de endividamento. Portanto, um fundo voltado para a estabilidade monetária e para prevenção de déficits públicos.

A função de poupança é realizada a partir dos depósitos anuais, em conjunturas de alta dos preços petrolíferos, e do incremento de dividendos ao principal do fundo. Este 
fundo de poupança torna-se especialmente relevante para o país, diante da previsão (em função do envelhecimento da população e do amadurecimento dos campos petrolíferos noruegueses) de incremento das despesas com aposentadoria na mesma época em que, espera-se, as receitas petrolíferas começarão a cair (SERRA, 2005, p. 133-134).

Apesar de presentes em quase todos os países produtores de petróleo, ganhou notoriedade como caso de sucesso o fundo soberano norueguês, criado em 1990, que conta atualmente com um patrimônio de mais de 2,3 trilhōes de coroas (NOK), aproximadamente 420 bilhões de dólares (GOBETTI, 2009).

Para que o país acumulasse tamanho ativo financeiro, Gobetti explica que "foi necessário que poupasse a maior parte das rendas do petróleo. Isso foi possível não só por não ter dívida pública (mas, ao contrário, ser um credor líquido), como também pelo regime tributário e fiscal aplicado ao setor" (2009, p. 18). Mais adiante, o autor acrescenta que, "em certa medida, o modelo norueguês (bird-in-hand) pode ser visto como um caso extremo de poupança precaucional no qual o governo decide consumir apenas o equivalente ao rendimento do estoque já acumulado de ativos" (2009, p. 24).

O fato é que o depósito de recursos em um fundo desta natureza tem a capacidade de combater, ao mesmo tempo, três das mais significativas causas para a maldição do petróleo: 1) a volatilidade do preço do petróleo, 2) a doença holandesa e 3) a aplicação dos recursos em despesas correntes.

Com relação à primeira, tem-se que à medida que os recursos não são gastos imediatamente, mas poupados, possibilita-se a manutenção no nível da renda com a qual o Estado irá contar para cobrir seus gastos com o fornecimento de bens e serviços públicos. Estes serão cobertos pelas receitas non-oil, e, eventualmente, com aquelas decorrentes do retorno sobre o capital investido por meio do fundo. ${ }^{63}$ Ademais, propiciam a realização de uma política anticíclica, possibilitando ao Estado poupar nos momentos de alta do preço do petróleo, e gastar nas épocas de crise, evitando, assim, oscilações bruscas na renda do país, sem que para isso precise recorrer a empréstimos.

63 De um conjunto de 31 países petrolíferos, analisados por Ossowski et al. (2008), 21 estabeleceram algum tipo de fundo (16 deles posteriores a 1995) para o qual canalizam parte das receitas do petróleo. “(...) Em termos operacionais, alguns países seguem regras discricionárias ou parcialmente dependentes do orçamento, depositando no fundo a receita excedente ao previsto no orçamento, mas a maioria adota regras rígidas para os depósitos e os saques, referenciadas em porcentuais preestabelecidos das receitas ou em determinados preços do petróleo - um teto anteriormente do qual as receitas são transferidas para o fundo e um piso abaixo do qual os recursos são sacados" (WULFF, 2009, p. 15). 
Ao mesmo tempo, o fato de essas receitas não serem postas diretamente em circulação no mercado dificulta que o seu ingresso promova a supervalorização da moeda local, que leva ao fomento das importações, e, consequentemente, o enfraquecimento da indústria local, ou seja, evita a ocorrência da doença holandesa.

Ademais, quando se atribui aos fundos soberanos também uma feição de fundo de investimento, permite-se a reprodução do capital gerado com a atividade petrolífera, isto é, transforma-se a receita pública oriunda da alienação de um bem em uma fonte de renda permanente para as futuras geraçōes. Desse modo, converte-se uma receita de capital em uma receita corrente, passível de ser utilizada para cobrir gastos correntes.

No Brasil, foi instituído um fundo dessa natureza em 22 de dezembro de 2010, por meio da Lei n. 12.351, chamado de Fundo Social, que visa cumprir tanto o papel de fundo de estabilização, quanto de investimento.

Para a formação dessa poupança pública vinculou-se boa parte das receitas a serem arrecadadas com a atividade petrolífera no pré-sal. ${ }^{64}$ as quais não poderão ser utilizadas diretamente, destinando-se tão só a constituir poupança pública de longo prazo e a mitigar as flutuações de renda e de preços na economia nacional (art. 48, I e III). Para o atendimento da finalidade constante no artigo 48 , II, que visa oferecer fonte regular de recursos para o desenvolvimento social e regional, por meio de programas e projetos nas áreas previstas no artigo $47,{ }^{65}$ deverão ser utilizados apenas os recursos do Fundo Social provenientes do retorno sobre o capital (art. 51, caput), ou seja, não poderão ser utilizadas parcelas de

64 De acordo com o artigo 49 da referida norma, constituem recursos do Fundo Social: I - parcela do valor do bônus de assinatura destinada ao FS pelos contratos de partilha de produção; II - parcela dos royalties que cabe à União, deduzidas aquelas destinadas aos seus órgãos específicos, conforme estabelecido nos contratos de partilha de produção, na forma do regulamento; III - receita advinda da comercialização de petróleo, de gás natural e de outros hidrocarbonetos fluidos da União, conforme definido em lei; IV - os royalties e a participação especial das áreas localizadas no pré-sal contratadas sob o regime de concessão, destinados à administração direta da União, observado o disposto nos $\$ \$ 1^{\circ}$ e $2^{\circ}$ deste artigo; $V$ - os resultados de aplicações financeiras sobre suas disponibilidades; e VI - outros recursos destinados ao FS por lei.

65 No artigo 47 da Lei n. 12.351/2010 foram explicitadas as áreas a ser contempladas com recursos do fundo, como forma de promover o desenvolvimento social e regional, por meio do financiamento de projetos e programas vinculados a essas áreas. São elas: I - da educação; II da cultura; III - do esporte; IV - da saúde pública; V - da ciência e tecnologia; VI - do meio ambiente; e VII - de mitigação e adaptação às mudanças climáticas. Contudo, de acordo com o parágrafo $3^{\circ}$ desse mesmo artigo, "do total do resultado a que se refere o caput do art. 51 auferido pelo FS, cinquenta por cento deve ser aplicado obrigatoriamente em programas e projetos direcionados ao desenvolvimento da educação, na forma do regulamento". 
recursos do principal, mas apenas seus rendimentos. A única exceção a essa regra consta no parágrafo único do artigo 51, segundo o qual, "constituído o FS e garantida a sua sustentabilidade econômica e financeira, o Poder Executivo, na forma da lei, poderá propor o uso de percentual de recursos do principal para a aplicação nas finalidades previstas no artigo 47, na etapa inicial de formação de poupança do fundo”.

Com relação à política de investimentos do Fundo, determina o artigo 50 que ela terá por objetivo "buscar a rentabilidade, a segurança e a liquidez de suas aplicações e assegurar sua sustentabilidade econômica e financeira para o cumprimento das finalidades definidas nos artigos 47 e 48”, devendo ser definida pelo Comitê de Gestão Financeira do Fundo Social - CGFFS. Tal comitê terá sua composição e funcionamento estabelecidos em ato do Poder Executivo, assegurada a participação do Ministro de Estado da Fazenda, do Ministro de Estado do Planejamento, Orçamento e Gestão e do Presidente do Banco Central do Brasil (art. 52, $\$ 1^{\circ}$ ).

Para atuar como agentes operadores do Fundo Social, a União, a critério do CGFFS, poderá contratar instituiçôes financeiras federais, as quais farão jus à remuneração pelos serviços prestados (art. 54). Ademais, a lei autoriza a União a participar, com recursos do FS, como cotista única, de fundo de investimento, que deverá ser constituído por instituição financeira federal (art. 55).

Por fim, cabe destacar que os investimentos e aplicações do Fundo Social, seguindo os ensinamentos propostos pela doutrina econômica, deverão ser destinados preferencialmente à aquisição de ativos no exterior, mitigando-se, com isso, a volatilidade de renda e de preços na economia nacional (art. 50, parágrafo único).

\subsection{LIMITAÇÃO DO GASTO DAS RECEITAS PETROLÍFERAS DECORRENTE DA MUDANÇA DE INTERPRETAÇÃO ACERCA DA SUA NATUREZA JURÍDICA}

A classificação das receitas petrolíferas, por parte dos entes federativos no Brasil, como sendo uma receita corrente, tem gerado, ao longo dos anos, efeitos nocivos para o país, possibilitando a sua utilização para cobrir gastos com despesas de custeio.

Por ser um recurso não renovável, o petróleo extraído hoje, e, consequentemente, a receita pública obtida com a sua venda, não estará disponível amanhã, 
motivo por que é insustentável do ponto de vista econômico a manutenção de uma estrutura de serviços públicos cujo custeio seja financiado diretamente por meio dessas receitas. Por isso, é essencial que a sua aplicação seja planejada, e investida de modo que as gerações futuras tenham uma fonte de renda quando do esgotamento das reservas.

No entanto, percebe-se que no Brasil tem acontecido exatamente o oposto. Não faltam relatos de ineficiência e até mesmo malversação no uso das rendas petrolíferas, como se verifica, por exemplo, em reportagem da revista Exame, elaborada com base em dados fornecidos pelo site Info Royalties, da Universidade Cândido Mendes:

os municípios que recebem royalties e participações especiais pela produção de petróleo estão desperdiçando o dinheiro com o custeio da máquina pública, em vez de aplicar essas receitas em projetos de infraestrutura, desenvolvimento econômico, saúde e educação. Dados levantados pela Universidade Cândido Mendes (Ucam) e pelo Centro Federal de Educação Tecnológica (Cefet) de Campos mostram que, dos 12 municípios que têm mais de $40 \%$ das receitas vindas da exploração de petróleo, apenas dois investem mais da metade dos recursos. (...) Em 2005, o campeão do desperdício foi o município fluminense de São João da Barra, que investiu apenas $10 \%$ dos 45 milhões de reais que recebeu em royalties. O resto foi usado com o custeio da máquina pública (uma ampla gama de gastos que vão desde o cafezinho até a compra de remédios e gasolina para ambulâncias) e o salário de funcionários. Entre os maiores recebedores de repasses, Campos, líder no ranking, só investiu 15\% dos $672 \mathrm{mi-}$ lhôes de reais dos recursos do petróleo. Já Rio das Ostras, terceiro maior beneficiado, investiu, no período, 152 milhões - ou $60 \%$ - dos 262 milhões de reais repassados (2007).

A alteração na classificação das rendas petrolíferas, conforme sugerido no presente estudo, de receitas correntes para receitas de capital, alteraria o seu regime de aplicação, limitando o seu gasto a cobrir despesas de capital.

Essa mudança teria início, necessariamente, na classificação dos royalties lato sensu da Lei Orçamentária Anual da União, que passariam a ser registrados como receitas de capital, assim como deverá ocorrer com a receita obtida com a venda do petróleo in natura, obtido pela União por meio dos contratos de partilha da produção.

Uma vez registrados na Lei Orçamentária Anual do ente central como receitas de capital, estariam adstritos a financiar despesas de capital, que, segundo o artigo 12 da Lei n. 4.320/64, constituem investimentos, inversões financeiras e transferências de capital. 
Essa nova classificação da receita promovida pela União teria impacto direto também na forma como devem ser registradas as compensaçôes financeiras repassadas aos Estados e Municípios. Como o artigo 44 da Lei de Responsabilidade Fiscal veda a aplicação das receitas de capital para o financiamento da despesa corrente, elas não poderiam ser transferidas aos Estados e Municípios a título de transferência corrente, que é uma forma de despesa corrente, mas somente como transferência de capital, conforme explicado no item 5.5.5. Assim, os beneficiários dos recursos repassados também estariam limitados a utilizá-los em investimentos ou inversões financeiras, conforme determina o parágrafo $6^{\circ}$ do artigo 12 da Lei n. 4.320/64.

Tal alteração de paradigma interpretativo resolveria boa parte dos problemas de aplicação das rendas petrolíferas no Brasil, sem que para isso fosse necessária uma mudança legislativa. Bastaria que a Secretaria de Orçamento Federal, órgão do Ministério do Planejamento, Orçamento e Gestão, estabelecesse essa nova forma de classificação orçamentária, tal qual autoriza o artigo 17, inciso VII, do Anexo I do Decreto n. 7.675/2012.

Os impactos positivos seriam sentidos de maneira mais expressiva pelos entes subnacionais, para os quais praticamente não há limites ao uso das compensações financeiras visando cobrir despesas de custeio. Não haveria dificuldades em compatibilizar a interpretação aqui proposta com a regra do artigo $8^{\circ}$ da Lei n. 7.990/89, que impede a aplicação dos recursos no pagamento de pessoal e da dívida. Ambas são despesas correntes, de modo que a proibição da Lei de Responsabilidade Fiscal de se aplicar receitas de capital em tais finalidades apenas reforça o comando da Lei n. 7.990/89.

Além disso, apesar de não vir sendo aplicada, a vinculação de receitas petrolíferas contida no artigo 24 do Decreto n. 1, de 11 de janeiro de 1991, que impõe a sua aplicação exclusivamente em "energia, pavimentação de rodovias, abastecimento e tratamento de água, irrigação, proteção ao meio ambiente e em saneamento básico", não representa problema algum, pois o gasto com esses objetivos dificilmente corresponderá a uma despesa corrente.

$\mathrm{Na}$ esfera federal, a partir da edição da Lei n. 12.351/2010, determinou-se que os royalties percebidos pela União nos contratos de partilha bem como o resultado da venda da sua parte no excedente em óleo devem ser destinados a compor o Fundo Social. Não serão, portanto, gastos, mas depositados em um fundo, com a finalidade de gerar ativos para o país. Como, via de regra, é vedada a utilização de re- 
cursos do principal do fundo, sendo lícito ao ente central apenas dispor das receitas oriundas do retorno sobre o capital - as quais se constituem em receitas correntes -, a alteração na classificação das receitas petrolíferas não terá impacto nesse caso, salvo quando a União decidir utilizar parcelas do principal, situação em que estará adstrita a aplicar esses recursos em despesas de capital.

No que tange às demais rendas petrolíferas que ingressam no orçamento da União, que deveriam ser utilizadas para financiar projetos e programas de órgãos específicos (Ministério da Ciência e Tecnologia, Ministério de Minas e Energia, Marinha e Ministério de Meio Ambiente), a mudança na classificação dos royalties lato sensu teria reflexos profundos, forçando a utilização desses recursos em atividades que efetivamente propiciassem o aumento do capital físico estatal.

A alteração na classificação dos royalties lato sensu para fins de registro na LOA é um passo importante e essencial, mas restam algumas dificuldades. Como visto anteriormente, a doutrina econômica é unânime em demonstrar a necessidade de se aplicar esses recursos em investimentos. Resta, por fim, perguntar: o que o ordenamento jurídico brasileiro define como investimento e inversōes financeiras?

De acordo com a Lei n. 4.320/64, consistem em:

Art. 12. A despesa será classificada nas seguintes categorias econômicas: (...)

$\$ 4^{\circ}$ Classificam-se como investimentos as dotações para o planejamento e a execução de obras, inclusive as destinadas à aquisição de imóveis considerados necessários à realização destas últimas, bem como para os programas especiais de trabalho, aquisição de instalações, equipamentos e material permanente e constituição ou aumento do capital de emprêsas que não sejam de caráter comercial ou financeiro.

$\$ 5^{\circ}$ Classificam-se como Inversões Financeiras as dotaçôes destinadas a: I - aquisição de imóveis, ou de bens de capital já em utilização; II - aquisição de títulos representativos do capital de emprêsas ou entidades de qualquer espécie, já constituídas, quando a operação não importe aumento do capital; III - constituição ou aumento do capital de entidades ou emprêsas que visem a objetivos comerciais ou financeiros, inclusive operações bancárias ou de seguros.

Quando se compara a definição adotada pela legislação brasileira para tais termos com aquela utilizada em outros países, observa-se a existência de duas peculiaridades no caso pátrio. A primeira é a própria diferenciação entre as expressões, tendo em vista que nos demais países é costume adotar-se apenas a expressão investimento, que englobaria as duas realidades. 
De todo modo, tem-se que, do ponto de vista do órgão público, não há diferença entre investimento e inversões financeiras, pois em uma ou em outra conta classificam-se transações que geram mudanças patrimoniais.

A diferença está no impacto que a transação gerará nas contas macroeconômicas do governo. Os gastos com a construção de uma escola, por exemplo, sem nenhuma dúvida, devem ser classificados como Investimento, pois representam a criação de riquezas e o aumento da renda do país (PIB). Por outro lado, a compra de um prédio pronto não efeito positivo na renda, já que a transação enseja apenas a transferência da propriedade do bem; seria mero intercâmbio entre setores do sistema econômico: da família para governo, por exemplo, caso o prédio fosse adquirido de uma pessoa física (LRF, 2013).

O segundo ponto que chama atenção é o fato de a definição brasileira restringir em demasia o alcance das expressões, limitando-se a reconhecer como investimento ou inversão financeira tudo aquilo que represente apenas um acúmulo de capital físico. Sobre essa questão, Jérôme Creel e Gwenaëlle Poilon criticam a maneira restrita como se trata o termo investimento público, postura adotada não só no Brasil, mas também na União Europeia, para fins de efetivação da Regra de Ouro das Finanças Públicas nas leis orçamentárias dos países-membros. Sobre o tema, assim se posicionam:

Balassone and Franco (2000) consider that the "golden rule", as it is promoting public investment, will result in a bias in favour of physical assets, at the expense of health and education expenditures. Hence, the definition of "public investment" in national account statistics includes transactions that lead to changes in the stock of physical capital (like the construction of infrastructures or the purchase of computer hardware), but excludes large amounts of expenditures related to the accumulation of human capital, like training or R\&D. We agree that a broader assessment of "public investment" should be promoted (Blanchard and Giavazzi,2003), but only insofar as changes in the "accounting rules" are made possible, say, every 5 years - a delay known $e x$ ante - in order to prevent an opportunistic behaviour by the governments (2006, p. 11-12).

Nesse contexto, para efeito comparativo, eis como a expressão é definida nos países da América Latina: 


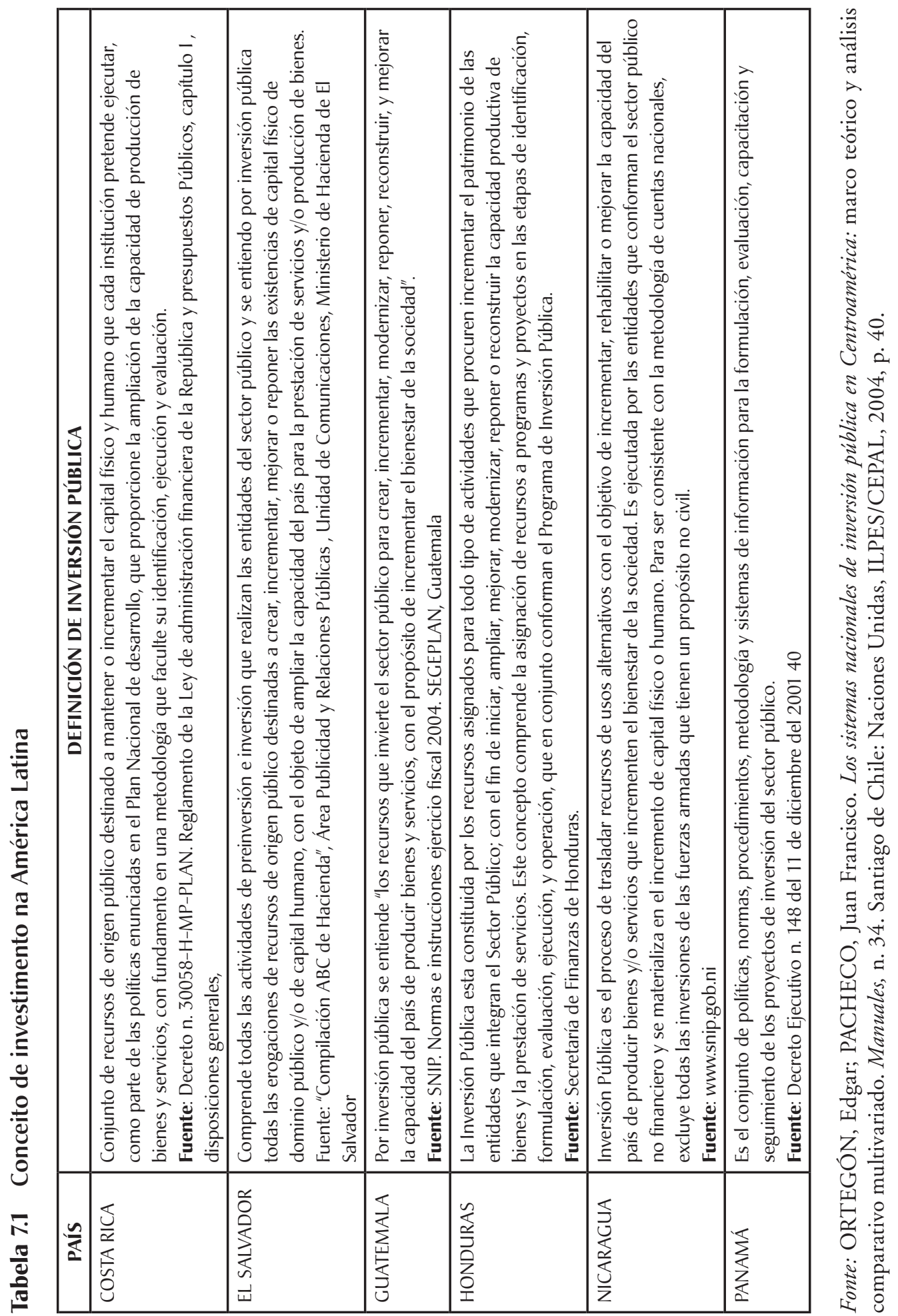




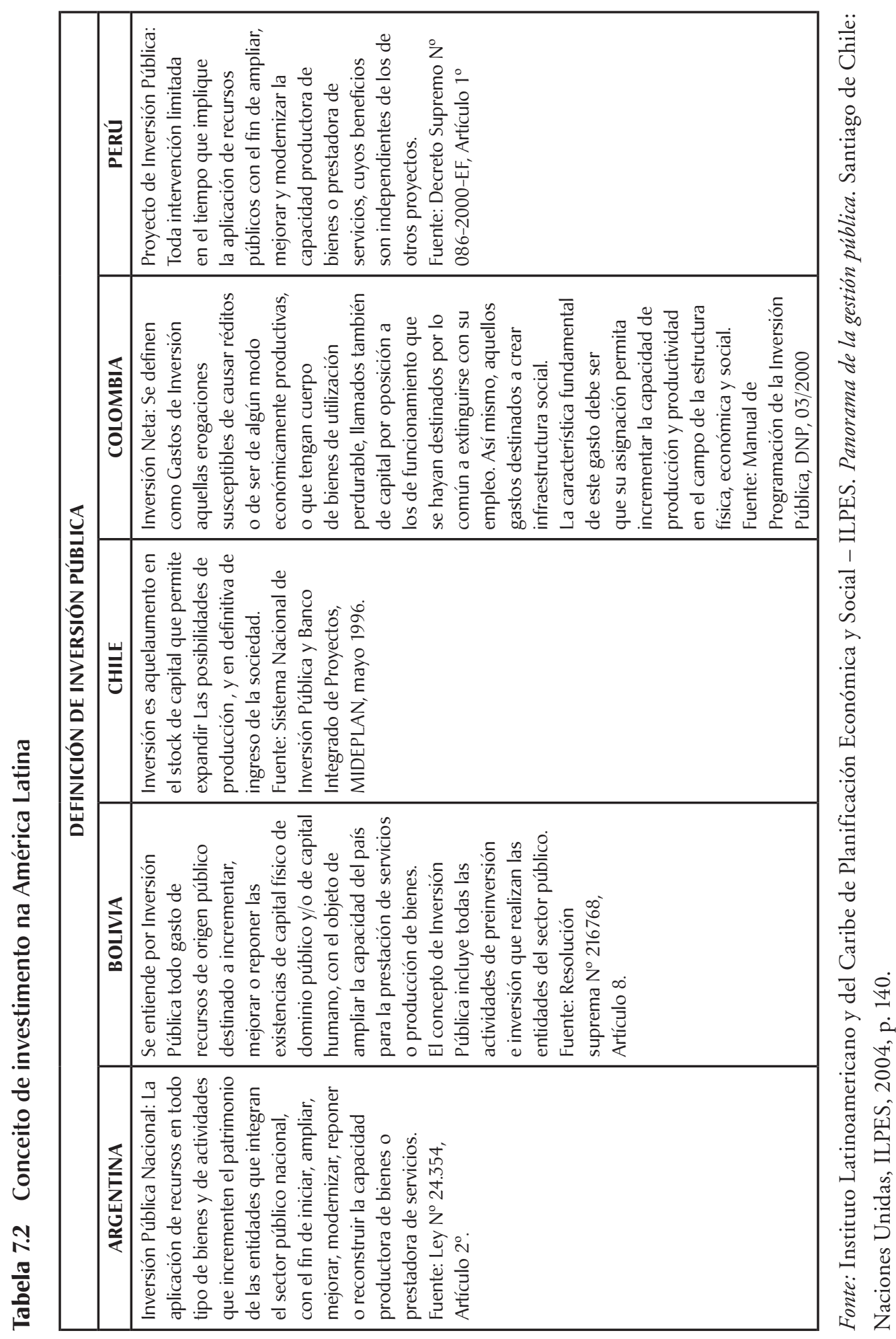


Perceba-se que em praticamente todos os países da América Central, bem como na Bolívia e no Chile, adota-se um conceito mais abrangente de investimento público, identificando-o não só com o aumento de capital físico, mas também humano. Verifica-se em países como a Costa Rica uma preocupação em atrelar essas ações a um planejamento estatal desenvolvimentista.

De fato, se mantido no Brasil um conceito muito restrito de investimento e inversóes financeiras, corre-se o risco de que deixem de ser aplicados recursos oriundos da atividade petrolífera, considerados receitas de capital, em finalidades de extrema importância para o desenvolvimento do país, como a educação. Nesta área, há uma série de ações que da maneira como é classificada a despesa atualmente, seriam consideradas necessariamente despesas correntes - como exemplo, a transferência de recursos federais destinados ao FUNDEB, em aumento ao valor mínimo por aluno. Tais ações, embora contribuam com o desenvolvimento de longo prazo do país, beneficiando as geraçôes futuras, na forma como a Lei n. 4.320/64 está redigida atualmente, não poderiam ser financiadas com as rendas provenientes da atividade petrolífera.

Apesar de não ser o escopo desta tese (mesmo porque se trata de uma questão tão profunda e complexa que mereceria um estudo próprio), pensa-se que o conceito de investimento utilizado pela legislação brasileira precisa ser revisto, de modo a incluir a aplicação de recursos para o aumento de capital humano como uma forma de investimento, e, consequentemente, como uma espécie de despesa de capital.

Contudo, tal necessidade de revisão do conceito legal de investimento no Brasil não anula nem diminui a importância de se rever a classificação jurídica dos royalties lato sensu hoje. Apenas impõe um outro desafio à União, que é alterar o conceito de investimento para fins de classificação da despesa orçamentária. A adoção da tese aqui proposta deve ser feita de maneira imediata, mesmo porque, ainda que se trabalhe com o conceito atual de investimento e inversões financeiras, as vantagens que se verificam do ponto de vista da eficiência no gasto público, com a proibição de aplicação das rendas petrolíferas em gastos correntes - conforme defendem os estudos econômicos citados ao longo do trabalho - superam em muito eventuais dificuldades que possam ser constatadas em face do conceito atual de investimento, sendo, portanto, um passo inicial e necessário. 
